\title{
Life Cycle Assessment of Residential Villa
}

\author{
Abdul Subhan Ansari \\ ${ }^{I}$ (Civil Department, Lords Institute Of, College/ JNTUH, INDIA) \\ ${ }_{2}^{2}$ (Civil Department, Lords Institute Of, College/ JNTUH, INDIA)
}

\begin{abstract}
Life cycle of building is developing research field. There are both natural and human sources of carbon dioxide emissions. Natural sources include decomposition, ocean release and respiration. Human sources come from activities like cement production, deforestation as well as the burning of fossil fuels like coal, oil and natural gas. Due to human activities, the atmospheric concentration of carbon dioxide has been rising extensively since the Industrial Revolution and has now reached dangerous levels not seen in the last 3 million years. Human sources of carbon dioxide emissions are much smaller than natural emissions but they have upset the natural balance that existed for many thousands of years before the influence of humans. Carbon dioxide is the major cause of global warming and global warming is caused by the emission of greenhouse gases. $72 \%$ of the totally emitted greenhouse gases is carbon dioxide (CO2), 18\% Methane and 9\% Nitrous oxide (NOx). The emissions of $\mathrm{CO} 2$ have been dramatically increased within the last 50 years and are still increasing by almost $3 \%$ each year. Recent investigations have shown that inconceivable catastrophic changes in the environment will take place if the global temperatures increase by more than $2^{\circ} \mathrm{C}\left(3.6^{\circ} \mathrm{F}\right)$. A warming of $2^{\circ} \mathrm{C}\left(3.6^{\circ} \mathrm{F}\right)$ corresponds to a carbon dioxide (CO2) concentration of about $450 \mathrm{ppm}$ (parts per million) in the atmosphere.

Building construction throughout the world contributes maximum share of carbon dioxide emission. A carbon footprint is historically defined as "the total set of greenhouse gas emissions caused by an individual, event, organization, product expressed as carbon dioxide equivalent. $\mathrm{CO}_{2}$ concentration is increasing in atmosphere due to the construction of buildings and materials used in it. Recent studies have shown the importance of carbon emission in the building materials. In this research work building material data is collected and analyzed and carbon dioxide emission is calculated through software called eco-it. This shows us the quantity of material and emission of carbon dioxide of individual materials. So we can try to reduce the carbon emission by using alternative materials.
\end{abstract}

Keywords: Carbon Emission, LCA, Materials, Environmental Impact assessment, Eco-it.

\section{Introduction}

1. Life-cycle assessment (LCA) is also known as life-cycle analysis, ecobalance, and cradle-to-grave analysis. It is a technique to assess environmental impacts associated with all the stages of a product's life from raw material extraction through materials processing, manufacture, distribution, use, repair and maintenance, and disposal or recycling. LCAs can help avoid a narrow outlook on environmental concerns by Compiling an inventory of relevant energy and material inputs and environmental releases; Evaluating the potential impacts associated with identified inputs and releases; Interpreting the results to help make a more informed decision.

2. The goal of LCA is to compare the full range of environmental effects assignable to products and services by quantifying all inputs and outputs of material flows and assessing how these material flows affect the environment. This information is used to improve processes, support policy and provide a sound basis for informed decisions.

3. According to a new study, in some regions more than a quarter of the warming from increased carbon dioxide is due to its direct impact on vegetation, in addition to its better-known effect as a heat-trapping greenhouse gases. Trees and other plants help keep the planet cool, but rising levels of carbon dioxide in the atmosphere are turning down this global air conditioner

4. Carbon emissions contribute to climate change, which can have serious consequences for humans and their environment. Carbon dioxide is the major cause of global warming. The carbon dioxide is released to the atmosphere where it remains for 100 to 200 years. This leads to an increasing concentration of carbon dioxide in our atmosphere which in turn causes the average temperature on Earth to raise.

5. As of beginning of 2007, the CO2 concentration is already at $380 \mathrm{ppm}$ and it raises on average $2-3 \mathrm{ppm}$ each year, so that the critical value will be reached in approximately 20 to 30 years from now.

6. There seems to be a agreement among the leading developed countries that the temperature increase caused by global warming must not exceed $2^{\circ} \mathrm{C}\left(3.6^{\circ} \mathrm{F}\right)$. To reach this target the annual global $\mathrm{CO} 2$ emissions have to be reduced from about 28 Giga tons in 2006 to 20 Giga tons of CO2 by the year 2050 and to 10 Giga tons of $\mathrm{CO} 2$ by the year 2100 according to IPCC. At the first glance, this does not look like a major 
reduction. However one should keep in mind that the world population will grow from 6.4 billion people in 2007 to about 9.5 billion people in 2050. At the same time more and more developing countries will progress their industrialization and as a result they will want to copy our western life style causing high $\mathrm{CO} 2$ emissions.

7. In construction there is lot of emission of carbon dioxide while manufacturation of building materials, transportation of building materials and use of building materials in construction. The burning of fossil fuels i.e. petrol, diesel etc releases carbon dioxide and other greenhouse gases. These carbon emissions raise global temperatures by trapping solar energy in the atmosphere. This alters water supplies and weather patterns, changes the growing season for food crops and threatens coastal communities with increasing sea levels.

8. The environmental impacts associated with building products are becoming increasingly important, as improvements in energy efficiency for new buildings lead to a larger relative impact in comparison to the operational impacts of buildings. Commonly referred to as "embodied impacts", they cover the impact associated with the manufacture, transport, installation, maintenance and disposal of building products. Construction products can be associated with a wide variety of environmental impacts, such as resource use and toxicity, but this briefing focuses on their global warming effects associated with the emission of $\mathrm{CO} 2$ and other GHGs (green house gases), described by the term, "embodied carbon.

9. The simplest way of explaining a product's embodied carbon is to say that it is the total quantity of carbon dioxide emitted from burning fossil fuels to manufacture both the product and all the raw materials it uses.

10. But in this research work we are focusing in calculation of carbon emissioin of materials used in residential villa and how can this be replaced by other materials or reduction of materials which emit more carbondioxide.So that we can contribute to save our environment by harmfuls GHGs(Green House Gases).As we have discussed above the harmful affects of carbon emission on our environment and human health. Calculation of carbon emission of particular material is the part of LCA.

\subsection{Carbon Emission}

Gases that trap heat in the atmosphere are called greenhouse gases. Carbon dioxide (CO2) is the primary greenhouse gas emitted through human activities .Carbon dioxide is naturally present in the atmosphere as part of the Earth's carbon cycle (the natural circulation of carbon among the atmosphere, oceans, soil, plants, and animals). Human activities are altering the carbon cycle-both by adding more CO2 to the atmosphere and by influencing the ability of natural sinks, like forests, to remove $\mathrm{CO} 2$ from the atmosphere. While $\mathrm{CO} 2$ emissions come from a variety of natural sources, human-related emissions are responsible for the increase that has occurred in the atmosphere since the industrial revolution.

Carbon dioxide enters the atmosphere through burning fossil fuels (coal, natural gas, and oil), solid waste, trees and wood products, and also as a result of certain chemical reactions (e.g., manufacture of cement). Carbon dioxide is removed from the atmosphere (or "sequestered") when it is absorbed by plants as part of the biological carbon cycle.

Many industrial processes emit CO2 through fossil fuel combustion. Several processes also produce $\mathrm{CO} 2$ emissions through chemical reactions that do not involve combustion; for example, the production and consumption of mineral products such as cement, the production of metals such as iron and steel, and the production of chemicals.

Carbon dioxide is constantly being exchanged among the atmosphere, ocean, and land surface as it is both produced and absorbed by many microorganisms, plants, and animals. However, emissions and removal of $\mathrm{CO} 2$ by these natural processes tend to balance. Since the Industrial Revolution began around 1750, human activities have contributed substantially to climate change by adding $\mathrm{CO} 2$ and other heat-trapping gases to the atmosphere.

\section{Building Materials}

Building material is any material which is used for construction purposes. Many naturally occurring substances, such as clay, rocks, sand, and wood, even, have been used to construct buildings. Apart from naturally occurring materials, many man-made products are in use, some more and some less synthetic. The manufacture of building materials is an established industry in many countries and the use of these materials is typically segmented into specific specialty trades, such as carpentry, insulation, plumbing, and roofing work. They provide the make-up of habitats and structures including homes.

\subsection{Materials used}

Materials used in Villa

We have divided all raw materials in 5 categories

i) Metals 
ii) Ceramics

iii) Polymers

iv)Elastomer

v)Fiber

\section{i) Metals}

The past fifty years have seen a steady growth of total steel production. In the 1950 s, the world steel production was about 200 million tons. In the past five years, the growth rate has accelerated. Total world crude steel production was 1,3435 billion tons in 2007 and 926,3 million tons in the first eight months of 2008. This is a $5,6 \%$ increase over the same period in 2007. In this century sustainable development will require a major increase in the volume of steel used and produced worldwide. Today, the world steel industry accounts for between $4 \%$ and $5 \%$ of total man-made greenhouse gases. The average CO2 intensity for the steel industry is 1,9 tons of $\mathrm{CO} 2$ per ton of steel produced. Taking into consideration the global steel production of more than 1,3 billion tons ,the steel industry produces over two billion tons of CO2.Over $90 \%$ of emissions from the steel industry come from iron production in nine countries or regions Brazil, China, EU-27, India ,Japan, Korea, Russia, Ukraine, and the USA. The global problem of climate change requires a global solution. Policies to encourage improved energy efficiency and reduced $\mathrm{CO} 2$ emissions are called for all over the world. The steel industry in industrialized countries, owing to efficiency improvements and structural changes, has made reductions in $\mathrm{CO} 2$ emissions during the past 40 years.

Metals used in building construction are plain carbon steel or mild steel.Qauntites of the metals is obtained from data collection and then it is analyzed and the total metals used in the whole construction is obtained and the carbon emission from particular metal is calculated with the help of eco-it software. Then the result is used to compare the carbon emission of all metal comparing other materials used in building construction. So that we can replace the particular metal or particular material to reduce carbon emission or to reduce the usage of the material.

\section{ii) Ceramics}

Carbon dioxide emissions in the ceramic and its reduction is one of the issues of international concern nowadays. The ceramic tile manufacturing is a highly energy-intensive production process and one of the main contributors to $\mathrm{CO} 2$ emissions since it contains several stages in which the products is subject to thermal treatment. As the largest producer of ceramic tiles in the world since 1993, China accounted for the maximal proportion of global emissions by ceramic tile manufacturing from fuel use and power generation, which made China the leader in $\mathrm{CO} 2$ emissions from the ceramic tile industry. In fact, $\mathrm{CO} 2$ emission from ceramic tile manufacturing reached 100 million metric tons in 2007 due to the production of 50 billion $\mathrm{m}^{2}$ ceramic tiles in China. Many studies have focused on $\mathrm{CO} 2$ emission from industries like cement manufactory, electricity generation, iron and steel, copper and etc, but few literatures focus on $\mathrm{CO} 2$ emission from ceramic tile manufacture. Furthermore, these studies usually concentrate attentions on data in macroscopic view(eg. Economic growth, population growth, energy conversion efficiency and so on), and pay little attention to manufacturing process and its application.

\section{iii) Polymers}

Polymer materials account for the highest growth area in construction materials. In basic terms, polymers are very long molecules typically made up of many thousands of repeat units. They include plastics, rubbers, thermoplastic elastomers, adhesives, foams, paints and sealants.

Well established applications of polymers in construction include areas such as flooring, windows, cladding, rainwater, pipes, membranes, seals, glazing, insulation and signage. With thousands of commercially available polymers new applications are continuously emerging.Confidence in the performance and properties of construction materials has always been important and may be of particular interest for polymers, which are relatively new compared to traditional material types that have been in use for hundreds or thousands of years. The introduction of polymeric materials can bring new concerns particularly relating to their longevity, how they will be affected by general ageing and weathering, the effects of pollution and what will happen to them at their end of life.

\section{IV) Elastomer}

Elastomeric paint is possibly the best exterior finish is elastomeric paint. This coating is so durable it can outperform even the best $100 \%$ exterior acrylic paint by 2 to 1 . Elastomeric paint forms a durable, tough film that provides a waterproof coating to almost any structure. This paint is resistant to sunlight, heat, cold and wind driven rain. It can be applied to all masonry surfaces, particularly stucco and concrete block. But is equally suitable for wood. You can eliminate cracking in masonry and many types of wood with this very thick 
coating. Elastomeric coatings have tremendous elongation characteristics, it will bridge and repair non-structural hairline cracks. Elastomeric Paint Doesn't Need Multiple Coats with 2 coats of elastomeric paint over an excellent primer, the cracks will be filled and water will not be able to penetrate when properly applied a $100 \%$ acrylic paint can last 10 years, but an elastomeric coating can last much longer.

\section{V) Fiber}

Mostly in villa plywood is used for doors. Plywood is a sheet material manufactured from thin layers or "plies" of wood veneer that are glued together with adjacent layers having their wood grain rotated up to 90 degrees to one another. It is an engineered wood from the family of manufactured boards which includes medium-density fiberboard (MDF) and particle board (chipboard). All plywood's bind resin and wood fiber sheets (cellulose cells are long, strong and thin) to form a composite material. This alternation of the grain is called cross-graining and has several important benefits: it reduces the tendency of wood to split when nailed at the edges; it reduces expansion and shrinkage, providing improved dimensional stability; and it makes the strength of the panel consistent across all directions. There is usually an odd number of plies, so that the sheet is balanced this reduces warping. Because plywood is bonded with grains running against one another and with an odd number of composite parts, it is very hard to bend it perpendicular to the grain direction of the surface ply.

\section{Data Collection}

Life Cycle Inventory data is data describing environmentally relevant inputs and outputs of a defined model of a technical system. The inputs and outputs consist of energy and matter that is used in the technical system to fulfil a well-defined function of the system, expressed by a functional unit. For example, the technical system can be a production site where polyethylene is produced. The function of the system can thus be defined as production of polyethylene, and the functional unit as Ex. $1 \mathrm{~kg}$ polyethylene. Examples of relevant inputs and outputs are natural resources, raw materials, energy ware, ancillary material, products, by-products, emissions to air, water and soil, residues. The scope of the technical systems that are studied in LCA range from individual process steps or production lines within a site, entire plants, transports and transportation routes, and complex composite systems such as production systems for specific products from cradle to gate. Technical system Inputs and outputs A model of a technical system A model of a technical system can have an inner structure, Ex. be composed of models

\subsection{Metals}

Metals are chosen for their durability, strength and resistance to weather, metals used in the construction industry serve a wide range of functions. The most common of them are carbon steel, aluminum, copper tubing and stainless steel, which each have their particular qualities and ideal uses.But every particular metal emits carbon dioxide in different quantities. Carbon steel is one alloy that is prized in the construction industry for its hardness and strength. It is typically used to make beams for structural framework. Carbon steel is classified on a scale of mild to very high, depending on how much carbon is present in the metal.

We have collected total steel data from $\mathrm{G}+1$ residential villa. Which contains total evaluation of steel from foundation, steel in columns i.e steel from floor columun,neck column and roof column, then steel in beams, tie beams, then last steel in slabs .Given below figure is the total steel evaluated in excel sheet.

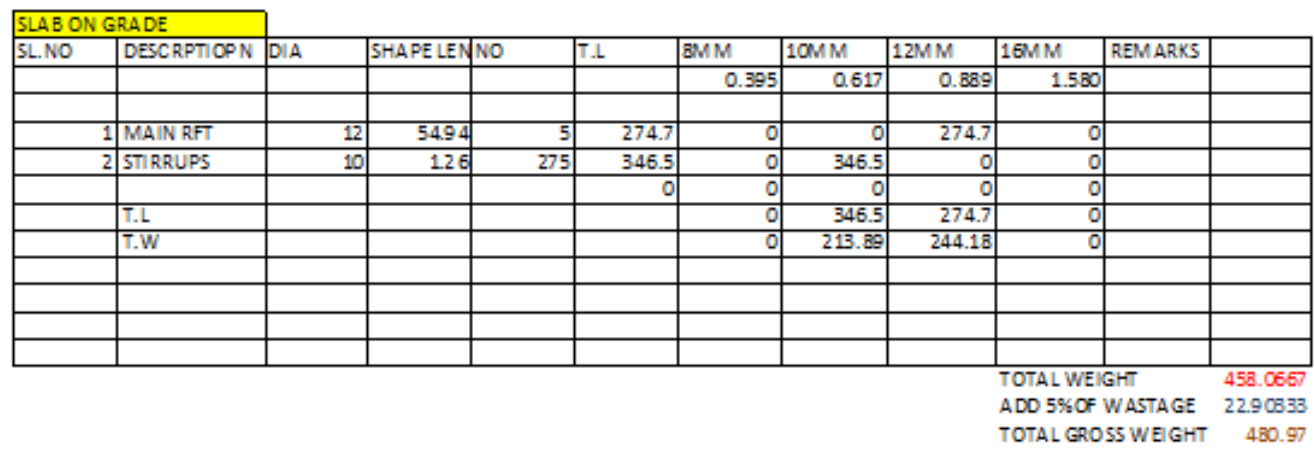

Sub Total Steel

1099.38

Total Ste el

4987.09 


\subsubsection{Ceramics}

- Ceramics have good compressive strength. Which makes ceramics good structural materials e.g., bricks in houses, stone blocks etc. Hardness, abrasion resistance, imperviousness to high temperatures and extremely caustic conditions allow ceramics to be used in special applications where no other material can be used.Metals, plastics \& ceramics are the significant engineering material. Among the three ceramic are largely synthetic. Ceramics comprise of Routine materials like cement, glass, porcelain, and brick \& strange material like spacecraft \& electronics. Due to the excellent power of resistance to heat \& chemicals, ceramics finds wide use in industries. Ceramic products resist to high temperatures, gases, water, salts \& acids based on their mineral component, Properties of all ceramic products are not identical they vary from each other. Ceramics are normally bad conductor of electricity; in certain cases when cooled, they turn into super conductor.

\subsubsection{Industrial Ceramics}

- Ceramic Tiles

- Cement

- Power Generation

- Steel Industry

- $\quad$ Fluid Handling

- Power Distribution Equipment

- Coal Washery

- Armour

- Structural, pipes, including bricks, roof tiles \& floor

- Refractory, such as kiln linings, gas fire radiant, steel and glass making crucibles

- White wares, sanitary ware, including tableware, pottery products and wall tiles

\subsubsection{Ceramics data collection}

We have evaluated all data of concrete separately in Ms Excel which contains concrete in foundation, Plain cement concrete, concrete in columns, concrete in beams, concrete in slabs, concreter in staircase, concrete in wall, concrete blocks, gypsum,flooring ceramics, flooring porcelain.

\section{Given below is the part of ceramics section}

\begin{tabular}{|c|c|c|c|c|c|c|c|c|}
\hline S.NO & DESCRIFTION & UNIT & NO & LENGTH & BREADTH & QTY & SKIRTING & REMARKS \\
\hline 1 & FLOORING(ground floor) & & & & & & & \\
\hline & G-15 MAID ROOM & M2 & 1 & 2.25 & 3.5 & 7.88 & 8.9 & \\
\hline & G-05 KITCHEN & M2 & 1 & 3.44 & 4.42 & 15.20 & 14.04 & \\
\hline & G-08STORE & M2 & 1 & 3.80 & 1.035 & 3.93 & 8.89 & \\
\hline & G-04 GUEST BATHROOM & M2 & 1 & 1.80 & 2.7 & 4.86 & & \\
\hline & G-14 POWDER ROOM & M2 & 1 & 0.95 & 1.18 & 1.12 & 3.31 & \\
\hline & G-13LAUNDRY & M2 & 1 & 1.90 & 1.512 & 2.87 & 5.02 & \\
\hline & G-16MAID BATHROOM & M2 & 1 & 1.50 & 1.512 & 2.27 & 5.22 & \\
\hline & & & & & & & & \\
\hline & & & & & & & & \\
\hline 2 & FLOORING(F.F) & & & & & & & \\
\hline & F-06 MASTER BR & M2 & 1 & 3.36 & 2.2 & 7.39 & & \\
\hline & F-08 BATHROOM 1 & M2 & 1 & 2.70 & 1.7 & 4.59 & & \\
\hline & F-O9 BATHRROM 2 & M2 & 1 & 1.90 & 2.69 & 5.11 & & \\
\hline & F-11 BATHROOM 3 & M2 & 1 & 1.90 & 2.69 & 5.11 & & \\
\hline & & & & & & o & & \\
\hline & & & & & & o & & \\
\hline & & & & & & 60.3386 & & \\
\hline
\end{tabular}

\subsection{Polymers}

Polymers have become increasingly important as engineering materials in the past decade and applications in the construction industry are expanding. Bulk polymers are used in applications such as pipes and conduit, wire and cable, foundations, fittings, roofing, flooring and insulation. Fiber reinforced plastics have recently been introduced for this application and have the advantage over PVC of not requiring additional reinforcement. Polymer foams are extensively used for insulation, primarily polystyrene, PVC, phenolformaldehyde and polyurethane. Structural foams have also been developed from materials such as polyolefin's, polycarbonate and ABS. Polymers used in residential villa is polypropylene water storage tank. Evaluation of water tank is given below in figure 
Triple- Layer W a ter Tank

\begin{tabular}{|c|c|c|c|c|c|c|}
\hline & Capacity & Diam eter & Length & Manhole Dia. & weight & Height $(m \mathrm{~m})$ \\
\hline Code $\mathrm{No}$ : & (LITRES) & $(\mathrm{INCH})$ & $(\mathrm{INCH})$ & $(\mathrm{IN} \mathrm{CH})$ & & \\
\hline & & & & & & \\
\hline & & & & & & \\
\hline CCWS -500.0 & 5000 & 78.7 & 78.7 & 37 & $100 \mathrm{~kg}$ & 1700 \\
\hline
\end{tabular}

\subsection{Elastomers}

An elastomer is a polymer with viscoelasticity having both viscosity and elasticity and very weak intermolecular forces, generally having low Young's modulus and high failure strain compared with other materials .The term, which is derived from elastic polymer, is often used interchangeably with the term rubber, although the latter is preferred when referring to vulcanisates. Each of the monomers which link to form the polymer is usually made of carbon, hydrogen, oxygen or silicon. The main elastomer used in this research work is paint and given below is the part of calculation of total paint in residential villa.

\begin{tabular}{|c|c|c|c|c|c|c|c|}
\hline S.NO & DESCRIPTION & UNIT & NO & LENGTH & BREADTH & PAINT\&PL & REMARKS \\
\hline 1 & FLOORING(ground floor) & & & & & 0 & \\
\hline & G-02 GUEST BED ROOM & M2 & 1 & 4.60 & 4.52 & 20.79 & \\
\hline & G-01 ENTRANCE LOBBY & M2 & 1 & 2.07 & 2.4 & 4.97 & \\
\hline & G-07 STAIR & M2 & 1 & 3.80 & 1.91 & 7.26 & \\
\hline & G-15 MAID ROOM & M2 & 1 & 2.25 & 3.5 & 7.88 & \\
\hline & G-08 STORE & M2 & 1 & 3.80 & 1.035 & 3.93 & \\
\hline & G-14 POWDER ROOM & M2 & 1 & 0.95 & 1.18 & 1.12 & \\
\hline & & & & & & & \\
\hline & & & & & & & \\
\hline 2 & FLOORING(F.F) & & & & & & \\
\hline & F-04 MASTER BEDROOM & M2 & 1 & 4.00 & 4.52 & 18.1 & \\
\hline & F-02 FAMILY LIVING & M2 & 1 & 5.90 & 3.71 & 21.9 & \\
\hline & F-11 BEDR OOM 3 & M2 & 1 & 3.68 & 3.925 & 14.4 & \\
\hline & F-09 BEDROOM 2 & M2 & 1 & 3.89 & 4.038 & 15.7 & \\
\hline & F-07 BEDR OOM 1 & M2 & 1 & 4.06 & 3.8 & 15.4 & \\
\hline & F-01 STAIR & M2 & 1 & 3.99 & 2.68 & 10.7 & \\
\hline & & & & & & 0 & \\
\hline & & & & & & 142.2085 & \\
\hline
\end{tabular}

\section{Total Paint}

\subsubsection{Fiber}

Wood is a porous and fibrous structural tissue found in the stems and roots of trees and other woody plants. It is an organic material, a natural composite of cellulose fibers that are strong in tension and embedded in a matrix of lignin that resists compression. Wood is sometimes defined as only the secondary xylem in the stems of trees.

\subsubsection{Plywood}

Plywood is a sheet material manufactured from thin layers or "plies" of wood veneer that are glued together with adjacent layers having their wood grain rotated up to 90 degrees to one another. It is an engineered wood from the family of manufactured boards which includes medium-density fiberboard (MDF) and particle board chipboard.

\subsubsection{Fiber used in villa}

Now days there is trend of plywood throughout the world. In villas there is increased use of plywood .Given below is the calculation part of plywood

\section{Wooden Doors}

\begin{tabular}{|c|c|c|c|c|}
\hline S.NO & Length $(\mathrm{mm})$ & Breadth $(\mathrm{mm})$ & Thickness $(\mathrm{mm})$ & Weight \\
\hline & & & & $\mathrm{kg}$ \\
\hline 1 & 2040 & 830 & 40 & so \\
\hline & No. of Door & & & \\
\hline G. Floor & 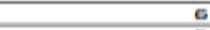 & & & \\
\hline Floor 1 & 5 & & & \\
\hline Total & 11 & & & \\
\hline
\end{tabular}

\subsection{Eco it}

\section{Software Used}

1. ECO-it allows you to model a complex product and most of its life cycle in a few minutes. ECO-it calculates the environmental load, and shows which parts of the product's life cycle contribute most. With this information you can target your creativity to improve the environmental performance of your product. 
2. ECO-it comes with over 500 ReCiPe environmental impact (ReCiPe) and carbon footprint (CO2) scores for commonly used materials such as metals, plastics, paper, board and glass as well as production, transport, energy and waste treatment processes.

3. This PC program can be installed on Windows XP/7 environment, 32-bit version. The current setup file available for download requires $2.7 \mathrm{MB}$ of hard disk space.

4. Our built-in antivirus scanned this download and rated it as virus free. The software lies within Photo \& Graphics Tools, more precisely Viewers \& Editors. This software was originally created by PRé Consultants B.V. Commonly, this program's installer has the following filenames: Eco-it.exe and ECO_IT.exe etc. The most popular versions of the software 1.4, 1.3 and 1.2.

5. Software similar to ECO-it are, OB WMP11, Foto-Mosaik or Filter Forge Freepack - Metals.

6. ECO-it or Eco-indicator tool is a simple tool for Ecodesign.

7. It works with Eco-indicator scores based on the ReCiPe (RCP) method and $\mathrm{CO}_{2}$ equivalents.

8. $\mathrm{CO}_{2}$ equivalents represent the Greenhouse Gas emissions associated with a product or service.

9. The program structure is simple. There is a Main window with four pages:

10. Life cycle page, allows you to describe the product life cycle under investigation.

11. In LIFE CYCLE Window is basically an introductory window where project name, Author and Date of project is specified.

12. Project description, Database and methodology used is also specified.

13. Final calculation of life cycle is displayed at the bottom of this window.

14. Production page, where you can enter the hierarchical structure of the product, and specify the materials and production processes per part. These materials and processes are chosen from the Select a process dialog box. The database holds the ReCiPe values and $\mathrm{CO}_{2}$ equivalents of material-, energy- and transport processes.

15. Disposal page, where you can specify the waste scenario for the product or for different parts

16. Not all products are disposed of in the same manner.

17. ECO-it allows you to specify a specific waste scenario for your product by combining five standard waste scenarios.

a. Municipal waste

b. Household waste

c. Incineration

d. Landfill

e. Recycling.

18. User has to specify in what percentage disposal of waste is done in above listed five categories.

19. According to this specified percentages, $\mathrm{CO} 2$ equivalent is generated by default and displayed in last column.

\subsection{Working with Eco it}

\section{i. Starting Page}

In starting page or main page of software. There is fields for name of the project,date,description.Given below is the main page.

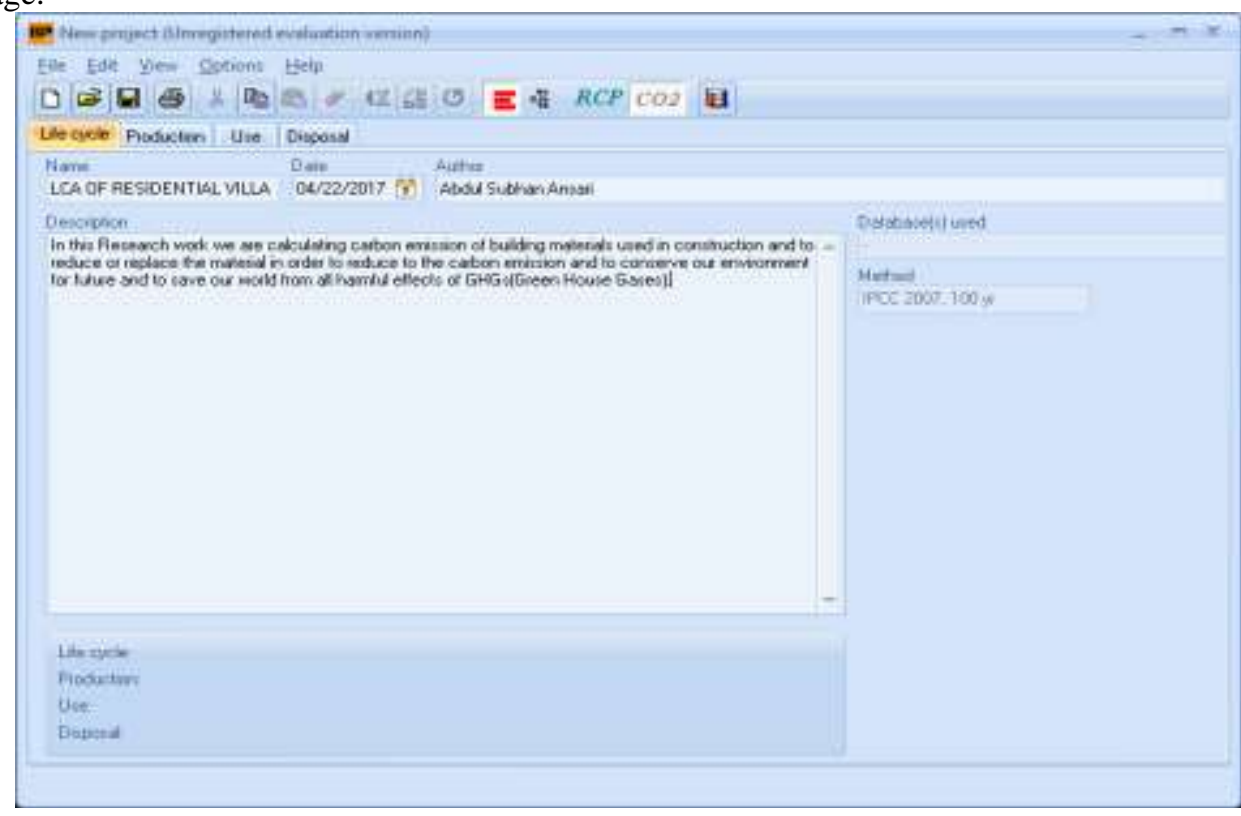




\section{ii. Data entry}

In this section data is manually entered in production field.Firstly main topic is entered i.e building material. Then its sub materials are entered name and quantity of material.

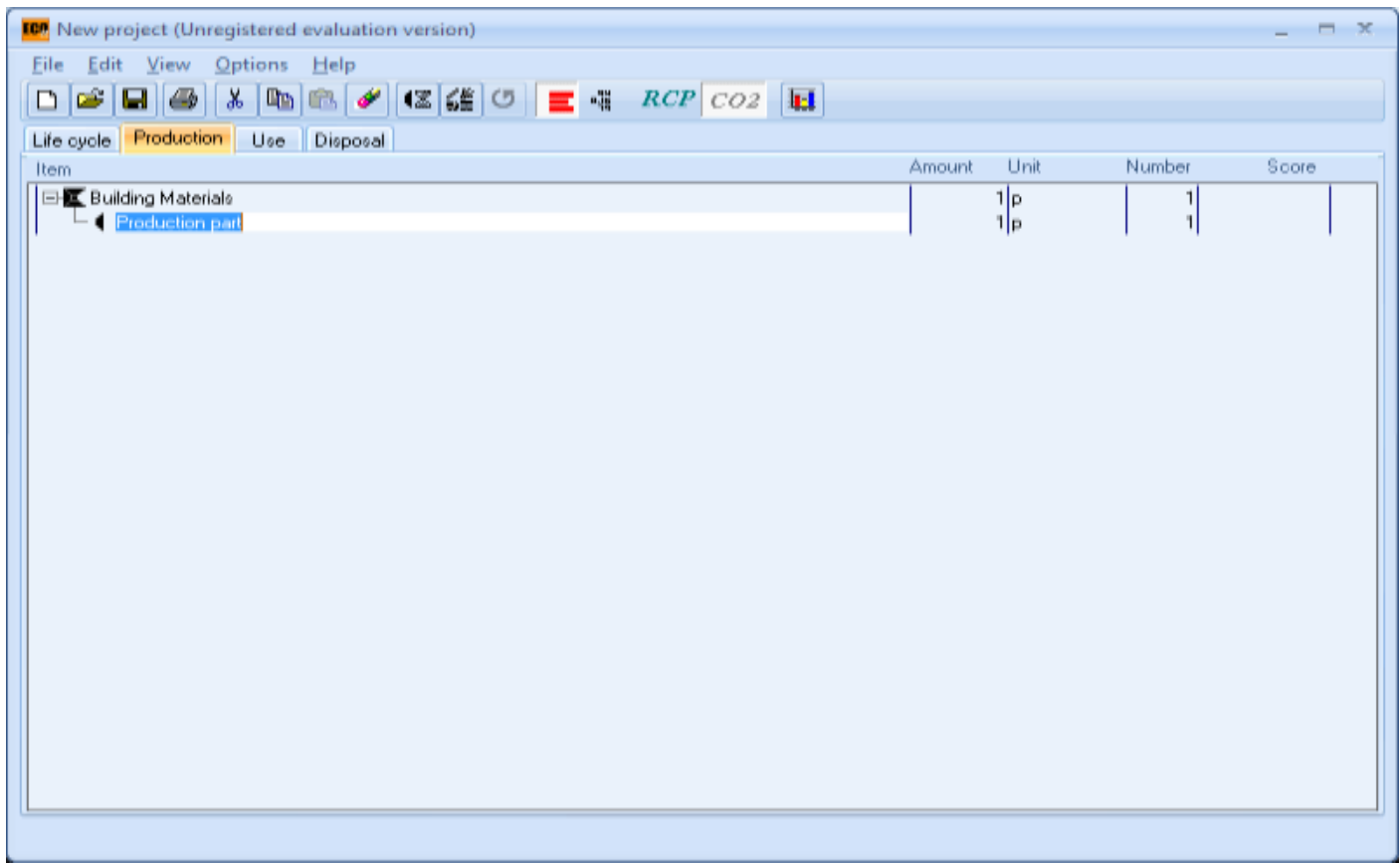

\section{iii. Calculation through eco it}

In software material names and carbon emission by particular material is already stored. If we provide the quantity of material it calculates and shows the carbon emission of material.

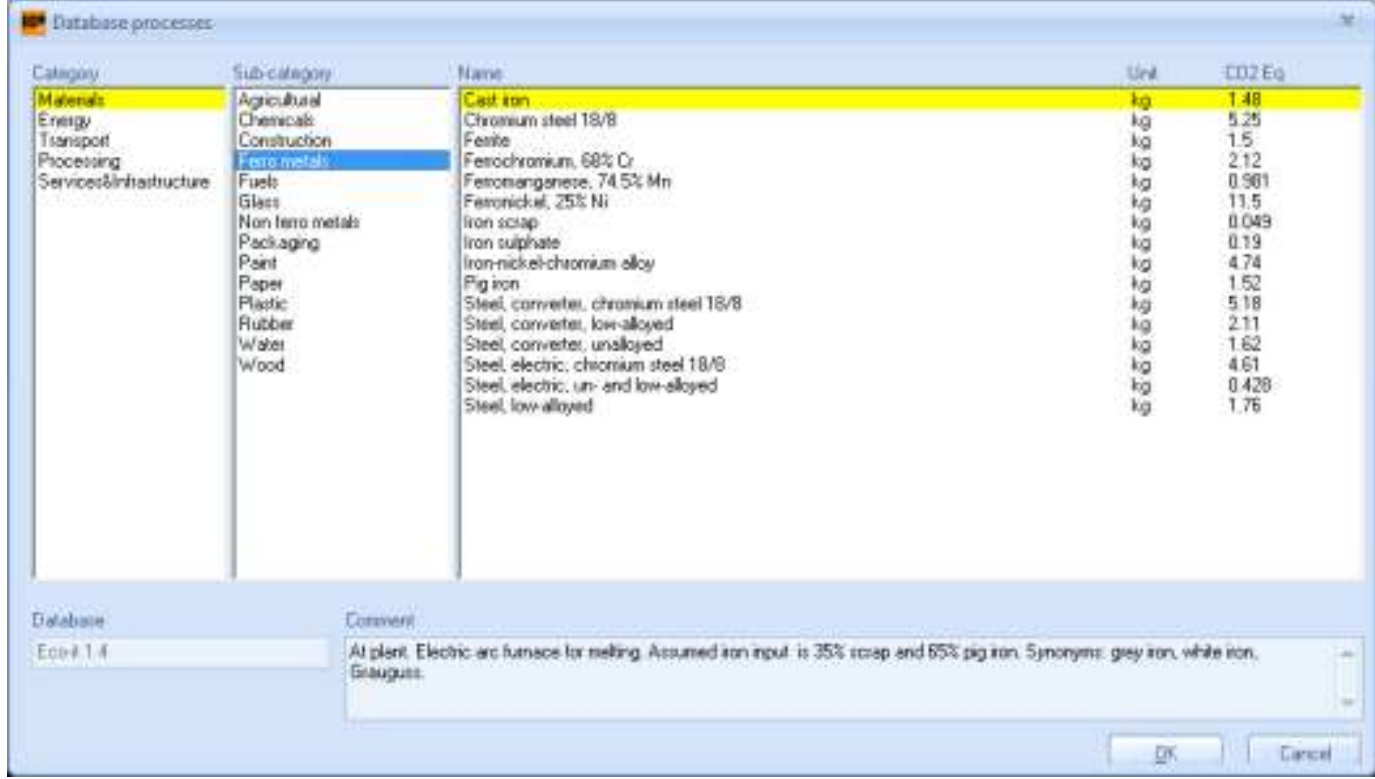

As shown above database of the software clearly shows material list and carbonemission per unit.

\section{Results And Discussion}

Results are displayed in the form of charts and bar graphs. By seeing the bar chart we can easily say that emission of carbondioxide of metals,ceramics,polymers,elastomers and fiber. Highest carbon emission is from fiber and so we replace the particular material or reduce the consumption of the fiber in order to reduce carbon emission. Second highest carbon emitter is ceramics, because the normal concrete,concrete blocks also emits high amount carbondioxide. But comparatively gypsum and ceramic tiles emit lesser amount of carbon as we have discussed above in the ceramics section.In order to reduce the carbon emission from concrete replacing 
the material by new materials whose carbon emission lesser than the concrete can help us in reduce GHGs(Green House Gases)which in return gives us large impact on reduction of global warming. Third highest is the metals. Many metals are used in construction but most probably steel is the main source of whole structure. And steel is widely used throughout the world. As the carbon emission of the steel is high you try to reduce the use of steel by replacing some other type of material whose carbon emission is less than steel. Fourth highest is elastomers because the quantity of material required is high and emission of carbon from that particular substance is also high. The main material is paint and paint is used in indoor and outdoor with large quantity to cover whole building. We can try to use new type of paints whose carbon emission is less as compared to other elastomeric paints. Fifth and the last is polymers .In this polymer section only calculation of polyethylene water tank carbon emission is calculated .So that's why it is low compared to all other sections.
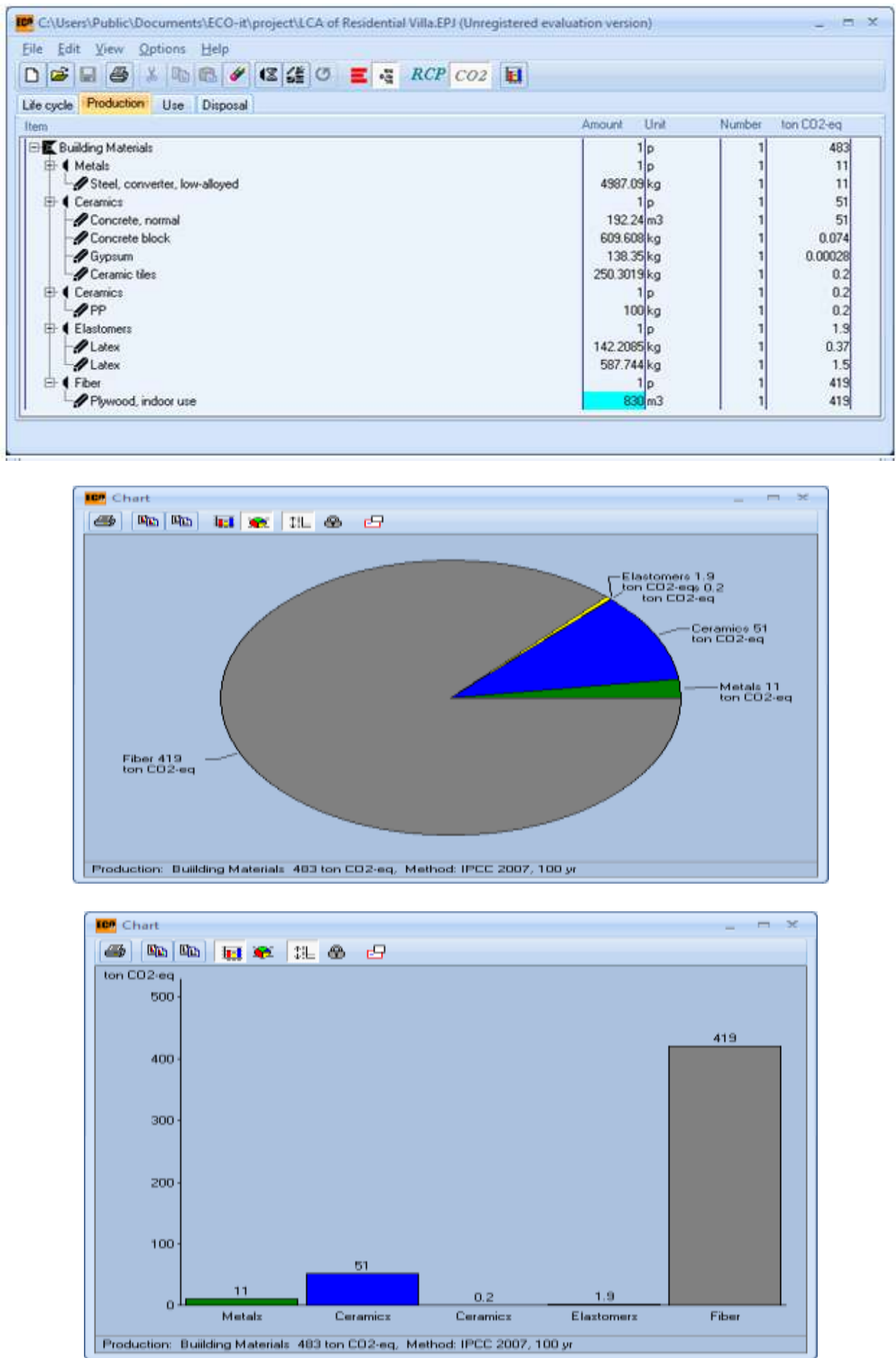


\section{Conclusion}

Carbon emission is calculated through a software eco it of a residential villa.In order to reduce carbon emission from materials used in building construction by reducing or replacing materials .So the GHgs (Green House Gases) is reduced in the atmosphere which in turn causes the average temperature on Earth to normalize. As we know from above results that fiber also produces much more carbon dioxide. In need of wood for building construction deforestation is taking place which causes natural disturbance in atmosphere. Plants absorb carbon dioxide for food preparation and balances level of carbon in atmosphere and by anthropogenic activities we are disturbing the natural carbon cycle. Global warming is primarily a problem of too much carbon dioxide in the atmosphere.So,we need to minimize the carbon emission by all means for healthy and better environment.

\section{References}

[1]. Embodied energy and carbon in construction materials G. P. Hammond and C. I. Jones 2008 'carbon footprint'

[2]. T Wiedmann, J Minx - Ecological economics research trends, 2008 - books.google.com Carbon footprint

[3]. BP Weidema, M Thrane, P Christensen... - Journal of industrial ..., 2008 - Wiley Online Library

[4]. Embodied energy of common and alternative building materials and technologies B.V. Venkatarama Reddy* , K.S. Jagadish Department of Civil Engineering, Indian Institute of Science, Bangalore 560 012, India

[5]. USE OF A HYBRID ENERGY ANALYSIS METHOD FOR EVALUATING THE EMBODIED ENERGY OF BUILDING MATERIALS J.A. ALCORN and G. BAIRD Centre for Building Performance Research, Victoria University of Wellington, PO Box 600, Wellington, New Zealand.

[6]. Identification of parameters for embodied energy measurement: A literature review Manish Kumar Dixit *, José L. Fernandez Solis, Sarel Lavy, Charles H. Culp College of Architecture, Texas A\&M University, 3137 TAMU, College Station, TX 77843-3137, United States Article history: Received 24 December 2009 Accepted 17 February 2010

[7]. Use of Natural-Fiber Bio-Composites in Construction versus Traditional Solutions: Operational and Embodied Energy Assessment Carmen Galan-Marin *, Carlos Rivera-Gomez and Antonio Garcia-Martinez Institute of Architecture and Construction Science, University of Seville, Seville 41012, Spain; Received: 20 April 2016; Accepted: 8 June 2016; Published: 13 June 2016

[8]. Embodied and operational energy of urban residential buildings in India Author: K.I. Praseeda B. V. Venkatarama Reddy M. Mans 2015 .

[9]. Comparison of embodied energy and environmental impact of alternative materials used in reticulated dome construction Juan C. Salcido a , Adeeba Abdul Raheem a, *, Srinivasan Ravi b Received 7 September 2015 Received in revised form 27 October 2015 Accepted 10 November 2015 Available online 14 November 2015

[10]. CO2 EMISSIONS IN THE STEEL INDUSTRY by M. KUNDAK, L. LAZI], J. ^RNKOAccepted - Prihva\}eno: 2008-01-10

[11]. Life cycle assessment as a tool in environmental impact assessment Arnold Tukker* TNO Institute of Strategy, Technology and Policy, P.O. Box 6030, 2600 JA Delft, The Netherlands Received 1 May 1999; revised 6 December 1999; accepted 9 December 1999 